\title{
AS LINGUAGENS DA ARTE: SUA INTERSUBJETIVIDADE VIA EDUCAÇÃO ESTÉTICA E FORMAÇÃO DOCENTE
}

Edilane Silva

Tabatta Andrade

Graciele Andrade Rangel

\section{Resumo}

A arte se apresenta de diferentes formas e é disseminada de maneiras diversas. No entanto, dificilmente encontramos nas instituições escolares - seja nas Formações Iniciais, Universitárias ou Continuadas - esse campo sendo apresentado sob o viés da Educação Estética sem que o mote seja a percepção do belo ou a forma como essa arte se apresenta. Pretendemos aqui pesquisar como esse conceito foi se constituindo, o que nos dará subsídios para a construção do nosso conceito de Educação Estética, fundamentando-o em nossas pesquisas futuras, uma vez que, consideramos a construção do conhecimento como uma relação intrínseca entre o conhecimento sensível e o inteligível, pautando-nos, assim, nos estudos de Duarte Jr. Estamos iniciando nossos estudos neste campo por intermédio do Grupo de Pesquisa Práticas Educativas e Formação de Professores (GPPF) e temos como foco o mapeamento das publicações da Revista Brasileira de Educação no período de 2008 a 2014, com o intuito de analisar como foi se construindo o citado conceito, entendendo de que modo vem sendo disseminado como instrumento de formação dos sujeitos imersos nos processos educativos e como tem realmente contribuído para a prática docente.

Palavras Chaves: Pesquisa; Educação Estética; Formação.

\section{Resumen}

El arte se presenta en diferentes formas y se difunde de varias maneras. Sin embargo, apenas se encuentra en las escuelas - ya sea en formaciones iniciales, la universidad o continuar - este campo se presenta bajo el sesgo de la educación estética sin que el lema es la percepción de la belleza y cómo se presenta este arte. Nos proponemos aquí para investigar cómo se constituyó este concepto, lo que nos dará subsidios para la construcción de nuestro concepto de educación estética, basándola en nuestra investigación futura, ya que consideramos la construcción del conocimiento como una relación intrínseca entre el conocimiento sensible e inteligible, que nos guía, por lo que en los estudios de Duarte Jr. estamos empezando nuestros estudios en este campo a través del Grupo de Investigación de Educación Práctica y formación del profesorado (GPPF) y nos centramos en el mapeo de las publicaciones de la Revista de Educación 2008-2014, con el fin de 
analizar cómo se construía el dicho concepto, la comprensión de cómo se ha difundido como una herramienta de formación para las personas inmersas en los procesos educativos y la forma en que realmente ha contribuido a la práctica docente.

Palabras clave: investigación; La educación estética; formación.

\section{Introdução}

Em 2013 participamos como cursistas de um Curso de Extensão promovido pela Universidade Federal do Estado do Rio de Janeiro (UNIRIO) que tinha como foco a Educação Infantil e como tema pensar o Corpo, a Arte e a Natureza como eixos fundamentais de trabalho tanto com os professores quanto com as crianças. A proposta principal era que os docentes deveriam, por meio de uma formação sensível e estética, serem afetados por práticas que primavam pela vivência, experimentação, ampliação de repertórios, escuta e olhar apurados. E dessa forma, transformarem suas práticas com as crianças, buscando vivenciarem também com elas uma Educação mais sensível, atenta e que dê voz e vez ao corpo, as artes e sua comunhão com a natureza. Após o curso e ainda em êxtase com as experiências a que nos submetemos, fomos convidadas a criar e participar de um grupo de pesquisa que pudesse continuar pensando em questões referentes à formação docente e à infância, nessa perspectiva de uma educação estética e formação do sensível que tem como principal referência João Duarte Júnior. Dessa forma, em 2014 nasce o grupo FRESTAS de pesquisa, visando pensar a Formação e a Ressignificação do Educador sob a ótica dos Saberes, Troca, Arte e Sentidos.

O primeiro passo da pesquisa foi buscar fundamentar e referenciar os conceitos com os quais gostaríamos de trabalhar, tais como: estética, vivências, experiência e formação. Consideramos o primeiro como o mais central, por isso, vários encontros se dedicaram a estudá-lo. Foram discutidas também, as possibilidades de pesquisarmos como vem sendo disseminado o conceito de Educação Estética entre os professores da rede e a forma como esse mapeamento seria feito. A proposta foi que nos dividíssemos em grupos e pesquisássemos a principio, os materiais que circulam nas mãos dos professores, através de teses, dissertações, artigos, revistas, redes sociais e demais instrumentos que trouxessem essa concepção para estes profisssionais. Ainda ficou estabelecido que o recorte fosse de 2008 a 2014, pois teríamos como base as Diretrizes Curriculares Nacionais de Educação Infantil (DCNEI's), já que 2008 foi o ano de discussão e construção desse documento mandatório de referência pedagógica para este segmento. Além disso, 
as pesquisas seriam tanto no campo acadêmico quanto nos materiais que chegam diretamente às mãos dos professores em suas instituições, como as revistas Nova Escola e Pátio, os documentos oficiais do município, dentre outras fontes, pois dessa forma também ficaria explícito como a concepção de Educação Estética é entendida pelo sistema de cada rede.

Começamos a ler alguns artigos, capítulos de livros indicados, pesquisas, mas ainda sem focar em um espaço específico. Fizemos uma seleção, e um dos textos que nos pareceu base para pensar a história dessa perspectiva foi o texto sobre abordagens e perspectivas estéticas, de Graciela Ormezzano (2007), onde é enfatizado que a Educação Estética teve diversas denominações em seus diferentes tempos históricos. A autora aborda inicialmente a história da estética e suas relações com os aspectos educacionais citando Platão, Aristóteles, Cícero, Santo Agostinho, São Tomas de Aquino - alguns expoentes do pensamento renascentista - e Kant, Hegel, Marx, Nietzsche, dentre outros do pensamento moderno. Aponta também as modulações efetuadas a partir do pensamento desses autores, a fim de acentuar como foi que emergiu uma primeira filosofia de educação estética na modernidade, desembocando numa vivência, isto é, na afirmação de que a experiência artística e a experiência estética configuram um mesmo horizonte de sentido. Ou seja, somos obras de arte, experimentadores de nós mesmos. Posteriormente aborda a história da educação artística e o provável desdobramento dela em educação estética no tempoespaço brasileiro.

É nesse momento em que o saber artístico entra em cena, sofrendo metamorfoses, isto é, produzindo novas propostas educacionais. Nas palavras da autora:

“A primeira alteração foi 'educação pela arte', que teve como objetivo o desenvolvimento das capacidades perceptivas, apreciativas e criativas; depois, 'educação artística', que visava a uma formação artística especializada, considerando as diversas linguagens expressivas; após, 'arteeducação', propondo uma visão educativa centrada no desenvolvimento cognitivo da leitura de imagens, a contextualização e o fazer artístico. Finalmente, a 'educação estética', muito pouco difundida, um processo em que cada sujeito sente, experimenta e vibra emocionalmente, de modo tal que seu potencial humano se expressa tanto na distinção da singularidade irrepetível como na forte percepção da união dinâmica com seus semelhantes, necessitando e sendo capaz de comunicar seus ideais e a complexidade da sua interioridade, que cobra vida nas ações e obras" (ORMEZZANO, 2007, p.15-16).

Por isso, pensar numa educação estética é pensar nos instrumentos que podem potencializar a sensibilidade, a criatividade e a percepção.

A autora citada acima enfatiza alguns conceitos e discussões de diferentes teóricos sobre a temática. Nesse contexto percebemos como nossa formação neste campo foi demarcada por 
diferentes influências (europeia, africanas, indígenas, etc.). No entanto, a escola jesuítica tradicional se pautou na repetição e memorização, sem haver espaço para criação e inovação, apenas a reprodução de um modelo padrão pré-estabelecido vigente do antigo continente. Diante disso, nos perguntamos: será que estamos passando por um período de retrocesso no nosso campo educacional, onde buscamos modelos, ciclos, apostilas de outros países para serem reproduzidos sem levar em conta a nossa realidade? Cultura? Diversidade? Retomaremos essa discussão com Faria (2014).

Então, por isso acontecer é que nós professores buscamos cursos, leituras, vivências, onde possamos ter como base, o sensível, os sentimentos, a cultura popular, o conhecimento acerca das vivências dos nossos alunos de forma individual e coletiva, aliando os conteúdos do currículo às vivências. Para ilustrar as nossas reflexões trazemos a fala do Professor Duarte Jr. - Doutor em filosofia pela UNICAMP - em uma entrevista realizada pela Professora Dr. ${ }^{\text {a }}$ Carla Carvalho em dezembro de 2012, quando diz do "conhecimento inteligível e do saber sensível", se reportando ao saber sensível como o ligado ao corpo e o inteligível à mente. Diante disso, acreditamos que nós enquanto professores devemos, em nossas propostas pedagógicas, propiciar uma aprendizagem que parta da criação de individual, sem modelos pré-estabelecidos, pois além de cada um ter suas histórias, nos constituímos enquanto grupo na coletividade, alinhando o conhecimento inteligível ao saber sensível, para que assim o desenvolvimento integral seja de fato vivenciado.

A partir desses esboços iniciais da pesquisa fomos nos aproximando de uma definição de Educação Estética como um exercício que se contrapõe a um modelo padrão no qual os posicionamentos e observações não estão só na superfície da arte, mas em sua essência, ampliando nossas percepções e buscando ser sensibilizados por ela para que tenham significado. Subtendemos que a racionalidade não pode ser dissociada da dimensão estética e concordamos com Conte (2013, p.92) quando diz que a "ação performativa é uma forma de racionalidade mais globalizante, porque proporciona um desdobramento realizador da própria comunicação intersubjetiva".

Na proposta das DCNEI's o princípio da Educação Estética é sensibilizar o outro. Entendemos que as artes não são apenas abstratas, mas parte de como agimos e aprendemos também por intermédio da cultura. A Estética é um pensamento que ganha vida através da absorção feita pelo individuo. Ela dialoga com a nossa realidade, está entrelaçada com o nosso cotidiano, por isso é difícil resumi-la em uma única disciplina.

Sua natureza deve ser entendida como busca de percepção, liberdade, fruição e de expressão conforme o afetamento - ou seja, a capacidade que terá em afetar, provocar, tocar o próprio 
indivíduo e os outros - pois é parte essencial e própria ao homem. A dimensão estética amplia nossa subjetividade, pois, apesar de ter estreita relação com a arte, vai além da apreciação do que é estipulado como o belo/feio e afins, pois se interpõe em como a arte se enreda no convívio humano, como nos construímos enquanto sujeitos, nos fazendo refletir acerca de suas dimensões e desdobramentos.

Mediante a esta subjetividade, a estética faz parte da formação educacional do individuo. Schiller citado por Duarte Jr. (1997) entende que o desenvolvimento só ocorre plenamente quando é oferecido ao homem meios de progredir intelectualmente através da sensibilidade, desde que esse desenvolvimento propicie o respeito, uma liberdade diferenciada, e principalmente valores que sejam válidos aos avanços individuais e coletivos. Nesta perspectiva, Habermas citado por Conte (2013) acredita que a partir das artes e da cultura é possível encontramos respostas à perplexidade do mundo, sugerindo que a educação pense na formação pedagógica "não como instrução ou mera reprodução de conhecimento, mas como a formação de sujeitos criadores de performances próprias". (Conte, 2013, p.82)

A partir desse pensamento assimilamos como proposta do nosso grupo, a vivência de novas e até mesmo velhas experiências. Porém com um novo olhar e com a premissa de sentir com o corpo todo, percebendo através do olhar do outro, de compartilhar/partilhar, de agregar, enriquecendo o nosso desenvolvimento enquanto ser social que aprende por meio do convívio, da memória, da troca, da experiência, pois a sociabilização acontece entre grupos, seja na faculdade, na família e/ou na escola; uma vez que a Educação Estética é a acumulação e a ponderação de tudo isso.

Percebemos o quanto esta perspectiva vem ganhando espaço dentro da Educação Infantil .Quando incentivamos o respeito pelo gosto do outro, propomos que pensem em suas atitudes, encorajamos a fazer algo diferente ou novo; quando apresentamos um mesmo aspecto, mas nas formas variadas em que se manifesta em outras culturas; quando oportunizamos as trocas, a apreciação de suas obras e de seus amigos e estimulamos a sensibilidade e a criatividade, vemos o quanto os princípios estéticos estão entrelaçados com a educação, ficando evidente que muito ainda precisa ser feito para um melhor uso do que a estética representa.

\section{Caminhos da pesquisa}

Diante dessas leituras elegemos para nossa pesquisa exploratória a Revista Brasileira de Educação $(\mathrm{RBE})^{\mathrm{i}}$ com levantamentos de dados de 2008 a 2014. Iniciamos uma investigação partindo de títulos, palavras chaves e leitura de resumos. Quando isso não nos deu conta, fizemos uma leitura dinâmica dos artigos. Buscávamos termos como: Educação estética, dos sentidos, do 
corpo, sensibilidade, etc. Ao terminarmos esses levantamentos houve mais uma revisão para a confirmação dos dados. Baseamo-nos para analisar esses artigos, em Educação estética como uma formação a partir do sensível.

Do ano de 2008 a 2014 foram publicados um total de 249 artigos em 23 edições até o mês de agosto. Esse total está distribuído da seguinte forma: 2008 (33artigos, em 3 edições), 2009 (30 artigos em 3 edições), 2010 (31 artigos em 3 edições), 2011 (29 artigos, em 3 edições), 2012 (29 artigos em 3 edições), 2013 (42 artigos em 4 edições) e 2014 (45 artigos em 4 edições). Desse total foram escolhidos oito artigos que traziam as discussões sobre o conceito de estética.

Ao lermos os artigos tínhamos como objetivo ressaltar: quais conceitos de Educação estética são defendidos? Como estes conceitos são concebidos? Existem diferentes concepções da Educação estética? Como se apresentam? Portanto iremos, por meio de um mapeamento e analise dos artigos, buscar este(s) conceito(s) nas revisões dos artigos selecionados, destacando suas concepções.

Observamos que a RBE aumentou suas edições a partir de 2013, de três para quatro e, consequentemente, a quantidade de artigos publicados. As análises demonstram um material rico em nos provocar quanto à necessidade de uma formação estética tanto para a criança quanto para a docência, em prol do desenvolvimento do individuo enquanto ser humano.

Conforme mencionado na introdução, um dos artigos que traz importantes contribuições para pensarmos na história da Educação Estética, é o de Faria (2014) quando, dentre outras coisas, enfoca a relação entre as atividades jesuíticas em terras brasileiras e mostra como isso atravessa a nossa educação até hoje. O referido autor nos traz reflexões sobre como nos construímos e constituímos, por meio de uma perspectiva diferente da que tínhamos aqui, até então, com os indígenas. Percebemos que a maior preocupação era colocar em ordem o que chamavam de corpo disperso. Dessa forma, entendemos que o corpo é uma das formas de controle social. E foi isso que aconteceu na Educação jesuítica. Mas principalmente, com o advento da Contrarreforma, “o que aconteceu foi um enrijecimento dos modos de prescrever o que se deveria conhecer, a maneira como deveriam ser repassados os conteúdos e quem deveriam ser os sujeitos considerados capazes de aprender o que era digno de conhecimento" (FARIA, 2014, p.439).Ao nos depararmos com esta afirmação percebemos como historicamente ainda temos, em nossas escolas, práticas enraizadas desde a invasão do Brasil pelos portugueses. Dessa forma, o conceito de Educação Estética que comumente se apresenta está pautado no controle do corpo e do conhecimento, feito por padrões estabelecidos, ancorados na repetição e não na criação.

Todavia, Barbosa mencionada por Omezzano (2007), nos revela que houve ruptura dessa visão ao problematizar a questão da leitura da obra de arte, ampliando-a para uma leitura de 
imagem, "considerando que outras imagens podem servir para aprendizagem gramatical visual" (2007, p.24) que está associada a uma proposta educacional contextualizada, ou seja, nesta perspectiva amplia-se o olhar e as percepções para além da educação formal institucionalizada. Nesta revisão ainda observamos que Souza (2014) discute uma Educação Estética dos sentidos no período do Estado Novo, via projeto da política de nacionalização, que visava uma "regeneração social" e a recondução dos sujeitos a uma postura de identificação (Identidade de brasilidade) criando assim uma realidade única, através de ritualizações e disciplinaridade de condutas. O que buscavam era uma uniformização em detrimento da consciência individual, e revela que esta forma de homogeneização (manobra) se deu de maneira sútil, pois parecia natural para as pessoas , com foco e atenção permanente nos sentidos.

Nesse sentido, a "a arte de disciplinar repousa nos sentidos" (SOUZA, 2014, p.401), pois através deles somos capazes de apreender o mundo e reestruturar as coisas. A percepção se efetua pelo hábito, ajudando a nos sentirmos integrados. Porém, se não refletirmos sobre essas percepções e sentidos, apenas reproduzindo-os, nos tornamos alvo da manipulação do poder.

Percebe-se que a modernidade veio construindo o que Souza (2014) chama de uma arquitetura sensitiva visando moldar as formas de o sujeito sentir, detectar, se sensibilizar, ou seja, as relações de poder tinham como alvo normalizar os espaços.

Souza (2014) mostra ainda que nesse período o sujeito tinha seus "sentidos" manipulados por um número reduzido de símbolos, imagens e experiências. Sendo orientados em razão de uma realidade sequestrada ou fabricados por objetos e imagens carregadas de sentidos e intencionalidades, dos projetos totalitários. Assim, utilizam os sentidos como fonte de disciplina. Neste contexto, esse período tendeu homogeneizar e manipular a percepção dos sentidos, numa perspectiva das relações de dominação; buscando através dessa arquitetura sensitiva mostrar uma realidade onde todos deveriam consumir aquilo que o Estado Novo pregava: uma percepção das coisas através de uma coesão social. Portanto, a perspectiva de dominação dos sentidos, requer sujeitos que apenas escutem, sintam e executem as ações como se fosse algo natural, não havendo espaço para uma reflexão crítica.

Entendemos que essa arquitetura sensitiva foi capaz de instituir uma crença, uma promessa, de comportar valores e normalizar os espaços e o tempo - o passado e o futuro em virtude daquele presente. Para isso, foi preciso ensinar os privilégios do sentido, do vivido, do carnal, da experiência e, por extensão, das significações sociais para tornar a realidade essencial, fixa e monumental. E assim cada imagem dessa nova arquitetura sensitiva foi pesada, como os lugares que ela ocupou, fixando-se como memória por meio de uma disciplina dos sentidos, da percepção efetuada pelo hábito. (SOUZA, 2014, p.404) 
Portanto, essa disciplinarização dos sentidos foi o principal dispositivo que possibilitou a criação de uma identidade do que é ser brasileiro.

E, sob o império dos sentidos disciplinados e habituados, essa mesma arquitetura acabou permitindo um "sentir brasileiro" que levou os sujeitos a experimentá-lo, saboreá-lo, tocá-lo, ouvilo, cheirá-lo e vê-lo no interior de um sistema cultural e simbólico construído pela maquinaria ordenadora do poder. (SOUZA, 2014, p.404)

O que se busca a princípio é uma sociedade dócil com uma disciplina dos corpos e dos sentidos voltada para suas necessidades. Souza (2014) afirma que isso é possível por meio de uma repressão efetiva e também pelo hábito, repetição e imagem que vão se naturalizando no imaginário como um espírito de unidade. Incute-se no sujeito a importância dele na construção dessa sociedade, não havendo, no entanto, uma reflexão sobre que sociedade é essa. Há também o sentido de pertencimento pela repetição de gestos e imagens encontradas em todos os locais. Essa forma de reconhecer-se não pode ser chamada de uma experiência estética, mas sim política, pois acontece pela manipulação, que tenta forjar a criação de um senso estético, no qual o sujeito se sinta inserido neste processo e autônomo para reproduzir o estabelecido.

Nestas revisões bibliográficas e por meio de nossas experiências/vivências percebemos que algumas infâncias ainda estão inseridas no contexto citado acima, pois ainda persistem posturas de silenciamento de corpos e sentidos, com práticas educativas equivocadas, que não oportunizam a expansão da capacidade criadora da criança.

Habermas citado por Conte (2014, p.81) nos diz que "a legitimidade de uma racionalidade prático-estética é formada pela validade que atribuímos ao seu poder de abrir nossos olhos à experiência vital, como um jogo entre autenticidade da expressão e adequação normativa". E entende que a ação performativa "diz respeito ao cerne da prática educativa, ao ato de comunicar, de mobilizar nos outros sujeitos novas construções do saber como também, de tornar presente a produção de novos sentidos (sensíveis e inteligíveis) para a formação docente." (CONTE, 2014, p.83). Acreditar que o conhecimento tem sua expressão apenas na linguagem, em técnicas e certezas é uma ingenuidade pedagógica.

\section{Considerações Finais}

Ao nos deparamos com todo esse material de pesquisa percebemos o quanto as "aprendizagens significativas" vem sendo debatidas. Todos os cidadãos têm direito à educação gratuita segundo a Constituição Federal de 1988, que ainda afirma que a educação tem como objetivo o desenvolvimento integral da pessoa. Os artigos encontrados por nós na pesquisa 
apontam para a necessidade de se construir políticas culturais dentro do âmbito escolar, pois se entende a escola como um espaço amplo para interação entre educação/artes/cultura, vinculando a vivência da criança com conteúdos propostos, para que deste modo possa haver um desenvolvimento intelectual e físico, onde o individuo seja preparado para conviver em sociedade. Para tanto, se faz necessário o acesso ao mundo das artes das incertezas e principalmente que a escola seja lócus de criação autoral e não de meras repetições descontextualizadas.

A Educação Estética que defendemos agrega em si, conhecimentos, experiências e um ensino que possibilite o desenvolvimento da percepção, da sensibilidade, da criatividade. É fundamental que esta se propague dentro dos espaços escolares, rompendo assim a lógica da Educação Artística focada no conhecimento enquanto disciplina. Torna-se, portanto, primordial a formação integral dos sujeitos.

No que tange à Educação Infantil, as pesquisas vêm indicando o quanto as crianças necessitam aprender a imaginar, pois na sociedade atual estamos sendo impactados pelo advento da tecnologia, com um excesso de informações que acabam sendo superficiais passageiras e muitas vezes sem significado. Sibila ( 2012) citada por Gasi ( 2013,p.264) amplia tal discussão ao enfatizar que :

(...) as novas tecnologias de comunicação, como os dispositivos móveis de acesso à rede, também acarretam uma mudança de paradigma em termos de estilo de vida e criação de subjetividades. A autora coloca que com a mudança nos vetores socioculturais, econômicos e políticos, mudam também os indivíduos e os corpos. E questiona: para que serve a escola? A questão no âmbito iluminista pode ser respondida historicamente, mas não dá conta do sujeito da contemporaneidade. Portanto, de que tipo de escola precisamos?

Nesse sentido é que buscamos uma formação diferente para dá conta dessa escola que entendemos como heterogênea. Para isso, se faz necessária uma formação de corpo todo, onde a criança possa investigar tudo ao seu redor e ressignificar suas experiências conforme é tocado pela sensibilidade.

É essencial que se pense nas infâncias não aquela que está no passado, cristalizada como pureza intocada ou ainda a que está por vir, permeada por uma era tecnológica, mas pensar na(s) infância(s) do hoje, do agora e como as crianças tem interpretado o mundo em que vivem. Como tem sido alimentada esta infầncia? Buscamos dar liberdade de expressão, ou ‘doutrinamos' para o controle e aprisionamento? Disciplinamento? Educamos para que as crianças possam criar ou apenas reproduzir por meio do olhar do professor? Essas questões nos remetem a Foucault (2008, p.119) que nos alerta que: 
Forma-se então uma política das coerções que são um trabalho sobre o corpo, uma manipulação calculada de seus elementos, de seus gestos, de seus comportamentos. (...) A disciplina fabrica assim corpos submissos e exercitados, corpos "dóceis".

Portanto, com o intuito de não fabricarmos "corpos dóceis" é que defendemos a manutenção de uma infância criadora, que se expande por meio da aprendizagem com a descontinuidade, a abertura de possibilidades, a imprevisibilidade dos acontecimentos momentâneos, tal como presente nos jogos das crianças. Nesse sentido, a arte aparece como espeço privilegiado de se brincar com a realidade, afinal, tem o dom de nos tocar e despertar inúmeros sentimentos e percepções. Para tanto, nos experimentos com a arte, temos utilizado variadas técnicas e diversos materiais, tais como: sombras, galhos secos, som, vibrações através do corpo, interações com as obras, entre outros. Isto vem mudando o modo como temos visto e vivido artes no nosso cotidiano, nos permitindo propor momentos de atividades criadoras mais profundas, indo além do que se já tem dado como pronto e finalizado.

Um fator que se mostrou essencial nos artigos, é que para que as artes possam ser disseminadas de forma significativa e ampla na infância, é necessário que o corpo docente invista em uma formação contínua que esteja inserida em práticas que contemplem e valorizem as artes, sempre se atualizando frente a elas. É dado um enfoque especial à arte contemporânea por estar mais próxima da atualidade em que vivemos, estando atento ao que ela representa e em qual contexto, pois a arte parte de um contexto histórico e não de algo "solto". Outro fator relevante e indispensável é despir-se de preconceitos ao se deparar com obras que nos causam estranhamento e que fogem ao consenso comum, mas entender que a arte é inovadora e nos rodeia em todo o momento e de variadas formas, não podendo ser rotulada como algo sempre previsível.

Deste modo, o professor deve se atualizar e buscar entender a arte como um suporte para experiências significativas, que se utiliza de modos diferenciados, seja pelas artes visuais, digitais, através dos sentidos e/ou de nossas memórias, pois a primeira formação de qualquer individuo é dada pela experiência de vida, do que nos passou e permanece registrado em nós. Isso demonstra que o docente não deve se prender a discursos prontos e sempre racionais. Deve sim haver as disciplinas formais, com atividades planejadas, mas estas devem compreender que a valorização da história de vida é fundamental para o desenvolvimento da criança.

A Educação Estética e as Artes Visuais se mostram indispensáveis na construção de um individuo sensível, questionador, reflexivo, que esteja aberto ao dialogo e a novas experiências, que seja autônomo, consciente e autor de sua própria arte.

Portanto, devemos fugir do modismo, mas considerar a necessidade de oferecer à criança um local que seja espaço de expressão e valorização da Identidade Infantil. E, com o intuito de 
não continuarmos fabricando os já citados "corpos dóceis" é que apostamos numa Educação Estética que encontra, na infância, o espaço privilegiado para a expansão da potência criadora. Porque nesse encontro com essa dimensão rica de nossa existência temos observado que podemos aprender com as crianças o exercício de experimentação de nós mesmos e do mundo, no jogo em que a imprevisibilidade é a força geradora da diferença e no qual as Artes Visuais têm funcionado como uma das peças de amplificação das sensibilidades em todos os atores desse processo.

\section{Referências Bibliográficas}

AQUINO, Julio Groppa. A difusão do pensamento de Michel Foucault na educação brasileira: um itinerário bibliográfico. Revista Brasileira de Educação [online]. 2013, vol.18, n.53, pp. 301324. ISSN 1413-2478. Disponível em: http://dx.doi.org/10.1590/S1413-24782013000200004 BRASIL. Presidência da República. Constituição 1988: Constituição da República Federativa do Brasil: promulgada em 5 de outubro de 1988. Brasília, DF. Disponível em:<http://www.planalto.gov.br/ccivil_03/constituicao/ConstituicaoCompilado.htm>. Ministério da Educação e Cultura. Conselho Nacional de Educação. Diretrizes curriculares nacionais para a Educação Infantil; Resolução n. 1, de 7/4/1999, Brasília: MEC, 1999.

CONTE, Elaine. Aporias da performance na educação. Revista Brasileira de Educação [online]. 2013, vol.18, n.52, pp. 81-99. ISSN 141-2478. Disponível em: http://www.scielo.br/pdf/rbedu/v18n52/06.pdf

DUARTE JR. Entrevista. Revista Contrapontos - Eletrônica, Vol. 12 - n. 3 - p. 362-367/ setdez.2012. Disponível em: http://www6.univali.br/seer/index.php/rc/article/viewFile/4039/2387. FARIA, Marcos Roberto. A organização de um corpo disperso uma analise jesuítica em terras brasílicas (1583). Revista Brasileira de Educação v. 19 n. 57 abr.-jun. 2014. Disponível em: http://www.scielo.br/pdf/rbedu/v19n57/v19n57a08.pdf

FISCHER, Rosa Maria Bueno. Docência, cinema e televisão: questões sobre formação ética e estética. Revista Brasileira de Educação [online]. 2009, vol.14, n.40, pp. 93-102. ISSN 14132478. Disponível em: http://dx.doi.org/10.1590/S1413-24782009000100008

FOUCAULT, Michel. Vigiar e punir. 39. ed. Rio de Janeiro: Editora vozes, 2011.

GASI, F. T. O projeto iluminista escolar e sua incompatibilidade com a sociedade contemporânea hiperativa. Galaxia (São Paulo, Online), n. 26, p. 263-265, dez. 2013. Disponível em: http://www.scielo.br/pdf/gal/v13n26/v13n26a22.pdf 
LOPONTE, Luciana Gruppelli. Arte e metáforas contemporâneas para pensar infância e educação. Revista Brasileira de Educação [online]. 2008, vol.13, n.37, pp. 112-122. ISSN 14132478. Disponível em: http://dx.doi.org/10.1590/S1413-24782008000100010.

OLIVEIRA, Marcus Aurelio Taborda de; LINHALES, Meily Assbú. Pensar a educação do corpo na e para a escola: indícios no debate educacional brasileiro (1882-1927). Revista Brasileira de Educação [online]. 2011, vol.16, n.47, pp. 389-408. ISSN 1413-2478. Disponível em: http://dx.doi.org/10.1590/S1413-24782011000200007

ORMEZZANO, Graciela. Debate sobre abordagens e perspectivas da educação estética. Em Aberto, Brasília, v. 21, n. 77, p. 15-38, jun. 2007. Disponível em: http://portal.educacao.salvador.ba.gov.br/site/documentos/espaco-virtual/espacoleituras/REVISTECA/revista $\% 20 \mathrm{em} \% 20 \mathrm{aberto} \% 20 \mathrm{n} \% \mathrm{C} 2 \% \mathrm{BA} \% 2077 . \mathrm{pdf}$ ROSA, Maria Inês Petrucci; RAMOS, Tacita Ansanello. Memórias e odores: experiências curriculares na formação docente. Revista Brasileira de Educação [online]. 2008, vol.13, n.39, pp. 565-575. ISSN 1413-2478. Disponível em: http://dx.doi.org/10.1590/S1413$\underline{24782008000300012}$

SCHILLER, J. Nos. XXII a XXIV sobre a educação estética do homem em uma sequência de cartas. In: DUARTE, JR. (Org.). O belo autônomo: textos clássicos de estética. Belo Horizonte: UFMG, 1997.

SOUZA, Rogério Luiz. A arte de disciplinar os sentidos o uso de retratos e imagens em tempos de nacionalização (1930-1945). Revista Brasileira de Educação v. 19 n. 57 abr.-jun. 2014. Disponível em: http://www.scielo.br/pdf/rbedu/v19n57/v19n57a07.pdf

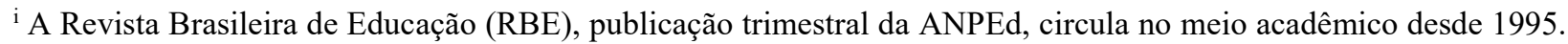
A RBE publica artigos inéditos que abordem temas associados à área da educação, resultantes prioritariamente de pesquisas.
} 